\section{Proteoglycan and collagen expression during human air conducting system development}

\author{
C. Godoy-Guzmán,' S. San Martin,' \\ J. Pereda ${ }^{1}$ \\ 'Department of Human Embryology, \\ School of Medicine, Universidad de \\ Santiago de Chile, Usach, Santiago; \\ 2Biomedical Research Centre, School \\ of Medicine, Universidad de Valparaíso, \\ Valparaíso, Chile
}

\section{Abstract}

The lung is formed from a bud that grows and divides in a dichotomous way. A bud is a new growth center which is determined by epithelial-mesenchymal interactions where proteins of the extracellular matrix (ECM) might be involved. To understand this protein participation during human lung development, we examined the expression and distribution of proteoglycans in relation to the different types of collagens during the period in which the air conducting system is installed. Using light microscopy and immunohistochemistry we evaluate the expression of collagens (I, III and VI) and proteoglycans (decorin, biglycan and lumican) between 8 to 10 weeks post fertilization and 11 to 14 weeks of gestational age of human embryo and fetus lungs. We show that decorin, lumican and all the collagen types investigated were expressed at the epitheliummesenchymal interface, forming a sleeve around the bronchiolar ducts. In addition, biglycan was expressed in both the endothelial cells and the smooth muscle of the blood vessels. Thus, the similar distribution pattern of collagen and proteoglycans in the early developmental stages of the human lung may be closely related to the process of dichotomous division of the bronchial tree. This study provides a new insight concerning the participation of collagens and proteoglycans in the epithelial-mesenchymal interface during the period in which the air conducting system is installed in the human fetal lung.

\section{Introduction}

The human lung undergoes dramatic changes in embryo-fetal life that are the result of growth and maturation. The formation of the air conducting system is the base of lung development and its dysmorphogenesis invol- ved lung malformations. The lung primordium begins around days 26-27 post-fertilization (pf), when the embryo has between $23-25$ pairs of somites with the generation of a bud that grows and divides in a dichotomous way, giving rise to the entire bronchial tree in a process called branching morphogenesis. ${ }^{1,2}$ Initially, each lung bud, called primary bronchus, divides within the mesemchyme to form a new generation of lung buds by week 5 of pf time, which after elongation and budding originate three secondary bronchi on the right lung and two on the left. These growth steps are the basis for the mature lobar airway organization of the lung. Thereafter, each lobar bronchus is divided dichotomously, generating the segmental bronchi organization. ${ }^{3}$ By the end of the pseudoglandular stage (week 15 of gestation), with the installation of the terminal bronchiole, ${ }^{4}$ the air conducting system is definitively installed. In this generational process each bud represents a new growth center in which epithelial-mesenchymal interactions are produced, and where extracellular matrix proteins (ECM) and growth factors are involved. ${ }^{5}$

Observations of human lung fetuses indicate that the branching pattern of the airway and its division are determined by epithelialmesenchymal interaction in which the ECM plays a leading role in the regulation of the growth and in the type design of the ramification. ${ }^{6}$ In this sense, the ECM molecules not only have a supporting role in cell architecture, but also an active role modulating cell proliferation and differentiation. ${ }^{7}$

In the opinion of several authors, the interaction of proteoglycans with collagen fibrils is important in the assembly and maintenance of the ECM during tissue growth and development. $^{8-12}$ Among the proteoglycans, decorin, biglycan and lumican, three small leucine rich proteoglycans (SLRPs) that show several structural and molecular similarities, are involved in the organization of the collagen fibril in the extracellular spaces. ${ }^{13-15}$

Gene ablation experiments have shown that mice lacking these SLRPs have collagen fibrillogenesis abnormalities leading to fragile skin, corneal opacity, osteoporosis or osteoarthritis. ${ }^{16-18}$ There is evidence that both decorin and biglycan bind to transforming growth factor $\beta$ (TGF- $\beta$ ), modulating its activity as mediator in growth inhibition. ${ }^{19-21}$ Moreover, while decorin is capable of directly suppressing cell proliferation, ${ }^{22,23}$ lumican can regulate collagen fibril organization, epithelial cell migration, and tissue repair. ${ }^{24}$ These results reinforce the concept that these molecules have a role in several biological processes related to growth, morphogenesis, and maturation of the extracellular matrix organization.

It is well known that epithelium-mesenchy-
Correspondence: Prof. Carlos Godoy-Guzmán, Facultad de Ciencias Médicas, Universidad de Santiago de Chile, Avda. Bdo. O'Higgins 3363, Correo 442, Santiago, Chile.

Tel. +56.2 .7183523 - Fax: +56.2 .4893465$

E-mail: carlos.godoy@usach.cl

Key words: human fetal lung, collagens, proteoglycans, extracellular matrix.

Acknowledgments: the authors gratefully acknowledge the valuable assistance of Dr. Lorena Sulz, Departamento de Embriología Humana, Escuela de Medicina, Universidad de Santiago de Chile, for her critical English analysis of this manuscript.

This work was supported by grants from DICYT (Universidad de Santiago de Chile, Santiago, Chile; grant no. 021001GG), DIPUV (Universidad de Valparaiso, Valparaiso, Chile; grant no. CI 05/2006), and Programa de Investigación Interdisciplinario (PIA) from Comisión Nacional de Investigación Científica y Tecnológica (CONICYT) (Anillos ACT-73), Chile.

Received for publication: 6 October 2011. Accepted for publication: 12 January 2012.

This work is licensed under a Creative Commons Attribution NonCommercial 3.0 License (CC BYNC 3.0).

(C) Copyright C. Godoy-Guzmán et al., 2012 Licensee PAGEPress, Italy

European Journal of Histochemistry 2012; 56:e29 doi:10.4081/ejh.2012.e29

mal interactions are key processes during the generation of the air conducting system of lung development, where ECM molecules such as collagen and proteoglycans are involved. Collagen distribution has been investigated, ${ }^{25}$ while proteoglycan expression and distribution is a matter not yet resolved in humans. The aim of our study was to evaluate the expression and distribution of SLRPS's proteoglycans in relation to the different types of collagens during the period in which the air conducting system becomes installed in human lungs.

\section{Materials and Methods}

Human embryos ranging from 8 to 10 weeks (wk) pf and fetuses from 11 to 14 wk of gestational age were used. Embryonic and fetal developmental age was determined based on the date of the last menstrual period and post collection measurements of limb size and shape. The embryos aged wk $8(n=2)$, wk 9 $(\mathrm{n}=2)$, and wk $10 \quad(\mathrm{n}=2)$ of pf time, were obtained from tubal ectopic pregnancies; the fetuses aged wk $11(n=3)$, wk $12(n=2)$, wk 13 $(n=2)$ and wk $14(n=2)$ of pregnancy were obtained from spontaneous abortion and con- 
served in $10 \%$ formalin in buffer phosphate at the Human Embryo Collection of the Universidad de Santiago de Chile. After fixation, lung samples were dehydrated and embedded in paraffin. Histological sections were processed for immunohistochemical analysis.

The study was approved by the local University Ethics Committee at the Universidad de Santiago de Chile (Authorization No. C-1004).

\section{Immunohistochemistry}

Immunohistochemistry was performed according to a previously established protocol. ${ }^{26}$ Briefly, in order to block endogenous peroxidase activity, sections were treated with $3 \%$ (v/v) $\mathrm{H}_{2} \mathrm{O}_{2}$ in phosphate buffered saline (PBS) for $30 \mathrm{~min}$. Each of the succeeding steps was followed by three PBS rinses. All steps were performed in a humid chamber in order to avoid dehydration of the sections. Antigen retrieval was carried out for all antibodies including the samples where the enzymatic treatment was performed, ${ }^{10,26-28}$ by immersing the slide in sodium citrate solution $(10 \mathrm{mM}$, pH 6.0) for $15 \mathrm{~min}$ at $95^{\circ} \mathrm{C}$. Non-specific staining was blocked by incubating the slide with Cas-Block solution (Zymed Laboratories, South San Francisco, CA, USA) for $10 \mathrm{~min}$.

Primary antibody incubation (Table 1) was achieved by subjecting the diluted sections in PBS containing $0.3 \%(\mathrm{v} / \mathrm{v})$ Tween 20, overnight at $4^{\circ} \mathrm{C}$. After rinsing in PBS, all sections were incubated for $1 \mathrm{~h}$ at room temperature with specific secondary antibody (Vector, Burlingame, CA, USA). Sections were incubated with RTU Vectastain kit (Vector) for $1 \mathrm{~h}$ at room temperature. Peroxidase reaction was observed using the NovaRED kit (Vector). Finally, the immunostaining sections were lightly stained with Mayer's haematoxylin (Merck, Darmstadt, Germany). For each immunohistochemical reaction, negative controls were used by incubating sections in normal rabbit or goat serum or by omitting the primary antibody. Human placenta was used as positive control for collagens. Cartilage of the lung samples was used as internal positive control for proteoglycans. Sections were examined under an IX81-Olympus microscope, and images were captured using a digital camera (Olympus DP-71) and the Olympus DP-BSW software.

\section{Results}

During all the study period, collagen I, III, VI, decorin and lumican were expressed in the basement membrane region of the bronchial tree (Figures 1 and 2). However, the immunostaining was more concentrated in the proximal airway ducts. Moreover, these collagens and proteoglycans were expressed in the epithelial-mesenchymal interface of the branch site, forming a sleeve around the bronchiolar ducts. The immunoreaction was more evident in the clefts of branching ducts. However, it was not continuous along the basement membrane region of the terminal bud. The proteoglycan biglycan was not expressed in the epitheliummesenchymal interface. Collagens I, III and VI were expressed in the subendothelial region of arteries, veins and capillaries (Figure 1). Decorin and lumican were not observed in blood vessels under any condition studied (Figure 2).

The expression and intensity of decorin, biglycan and collagen types III and VI in the lung mesenchyme retained their distribution during the study period. In contrast, lumican and collagen type I showed low immunoreaction from wk 11 of gestational age onward. Biglycan (Figure $2 \mathrm{~g}$ ) was observed at wk $8 \mathrm{pf}$ in the endothelial cells and in the blood vessel smooth muscle cells surrounding the terminal bud, but it was not detected in the mesechymal cell layer beneath the epithelial tubules. The biglycan immunostaining was observed only in blood vessels (Figure 2 g-i) located near the epithelium. Between wk 9 and 14 a network of blood vessels was observed in the whole lung, maintaining a close relationship with the airway structures. This immunoreactivity pattern was generally observed to be uniform throughout the capillary network of the lung.

The results of each of the individual structures have been summarized in the Table 2 .

\section{Discussion}

The results of the present study demonstrated the expression and distribution of collagens and proteoglycans at the epitelial-mesenchymal interface of bronchiolar duct and around blood vessels during the period in which the air conducting system of the human lung install. Decorin, lumican and all collagens types investigated were expressed in the epitelial-mesechymal interface, forming a sleeve around each bronchiolar duct from wk 8 to 14 of lung development, while collagens

Table 1. Immunohistochemical markers.

\begin{tabular}{|c|c|c|c|}
\hline Primary antibody & Specificity & Enzymatic pretreatment & Working dilution \\
\hline $\begin{array}{l}\text { Rabbit polyclonal } \\
\text { (Rockland) } \\
\text { Cat No. 600-401-103-01 }\end{array}$ & $\begin{array}{l}\text { Anti-human collagen I } \\
\text { Human procollagen } 1 \text { (I), mature } \\
\text { chain and heterotrimer collagen I }\end{array}$ & & $1: 1000$ \\
\hline $\begin{array}{l}\text { Rabbit polyclonal } \\
\text { (Rockland) } \\
\text { Cat No. } 600-401-105-01\end{array}$ & $\begin{array}{l}\text { Anti-human collagen III } \\
\text { Human procollagen } \alpha 1 \text { (III) }\end{array}$ & & $1: 2000$ \\
\hline $\begin{array}{l}\text { Rabbit polyclonal } \\
\text { (Chemicon, Int.) } \\
\text { Cat No. AB7821 }\end{array}$ & $\begin{array}{l}\text { Anti-human collagen VI } \\
\text { Human procollagen } 1 \text { (VI) }\end{array}$ & & $1: 2000$ \\
\hline $\begin{array}{l}\text { Goat polyclonal } \\
\text { (R\&D System) } \\
\text { Cat No. AF } 143\end{array}$ & $\begin{array}{c}\text { Anti-human decorin } \\
\text { aa 17-359 of human decorin core protein }\end{array}$ & $\begin{array}{c}\text { Chondroitinase } \mathrm{ABC} \text { (Seikagaku, Corp) } \\
0.2 \mathrm{U} / \mathrm{mL} \text { in Tris- } \mathrm{HCl} 20 \mathrm{mmol}, \mathrm{pH} 6.0 \\
1 \text { h at } 37^{\circ} \mathrm{C}\end{array}$ & $1: 100$ \\
\hline $\begin{array}{l}\text { Goat polyclonal } \\
\text { (R\&D System) } \\
\text { Cat No. AF } 2745\end{array}$ & $\begin{array}{c}\text { Anti-mouse lumican } \\
\text { mouse lumican shares } 88 \% \\
\text { aa sequence identity human mature lumican }\end{array}$ & $\underline{-}$ & $1: 200$ \\
\hline $\begin{array}{l}\text { Goat polyclonal } \\
\text { (R\&D System) } \\
\text { Cat No. AF } 2667\end{array}$ & $\begin{array}{c}\text { Anti-human biglycan } \\
\text { aa 18-368 of human biglycan } \\
\text { core protein }\end{array}$ & $\begin{array}{c}\text { Chondroitinase } \mathrm{ABC} \text { (Seikagaku, Corp) } \\
0.2 \mathrm{U} / \mathrm{ml} \text { in Tris- } \mathrm{HCl} 20 \mathrm{mmol}, \mathrm{pH} 6.0 \\
1 \text { h at } 37^{\circ} \mathrm{C}\end{array}$ & $1: 500$ \\
\hline
\end{tabular}


were expressed in the subendothelial region of blood vessels. Our observations give new additional information to the results of studies done on the macromolecular organization of the ECM during human lung development.

Using an inmunohistochemical approach, Wright et al. ${ }^{25}$ studied human lung develop- ment from 10 to 42 weeks of gestation, finding the expression of collagens I, III, IV, V and VI. They found that collagens were consistently present at branching points of the airways, suggesting that collagen would have a role in the initiation and stabilization of airway branches during lung development. Our results are similar and complementary to previous descriptions made by Wright et al. ${ }^{25}$ showing that collagens type I, III and VI are present very early in the epithelial-mesenchimal interface of the branching process. Moreover, during the study period we showed that not all types of collagen were present in

Table 2. Proteoglycan and collagen distribution in different region during human air conducting system development.

\begin{tabular}{|c|c|c|c|}
\hline Extracellular matrix molecules & Epithelial-mesenchymal interface & Endothelial cells & Subendothelial region \\
\hline Collagen I & + & - & + \\
\hline Collagen III & + & - & + \\
\hline Collagen VI & + & - & + \\
\hline Lumican & + & - & - \\
\hline Decorin & + & - & - \\
\hline Biglycan & - & + & + \\
\hline
\end{tabular}

,+ presences of the molecule; -, absences of the molecule.
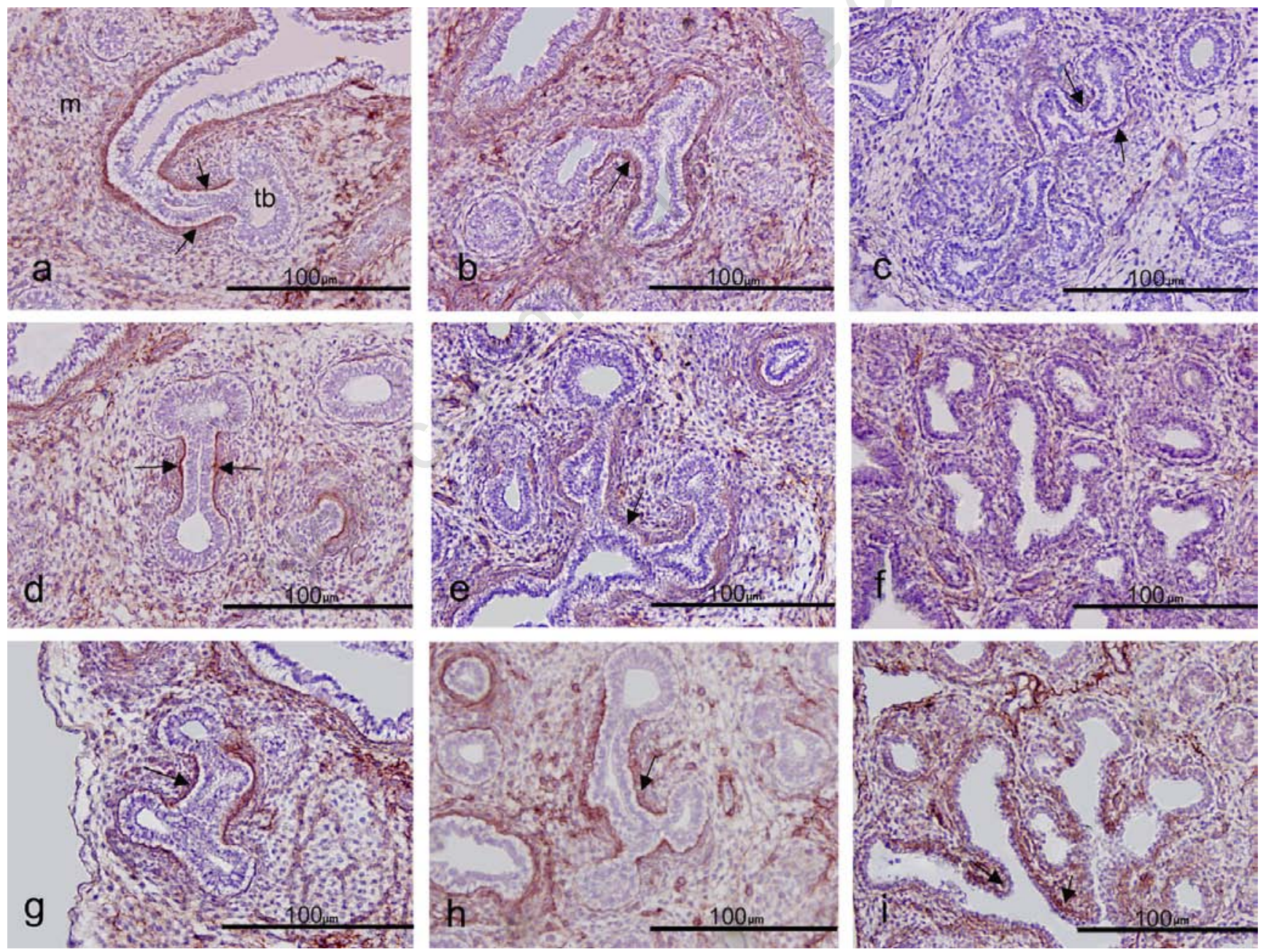

Figure 1. Immunoperoxidase stain for collagen type I (a-c), collagen type III (d-f) and collagen type VI (g-i). From wk 8 post-fertilization time (a, d, $\mathrm{g}$ ) collagen is expressed in the epithelial-mesenchymal interface in the branch site and forms a sleeve around bronchiolar ducts (arrows). The surface of the terminal buds is not stained. At $10 \mathrm{wk}$ pf time (b, e, h) the immunoreaction is present in the branching ducts clefts (arrows). At wk 14 of gestational age low immunoreaction for collagens type I is detected (c), but collagens type III (f) and VI (i) retain their distribution in the mesenchyme. $M$, mesenchyma; tb, terminal bud. 
the terminal bud surface, suggesting that the absence of collagen in this region may be necessary for the normal growth of the bronchial tree. The low immunostaining of collagen I from wk 11 gestational age onwards showed in the present work is different to the results obtained by Wright et al., ${ }^{25}$ who report an increase in immunostaining as gestation progresses. However, our results agree with those described by Kaarteenaho-Wiik et al. ${ }^{29}$ where a varied expression of precursors protein and mRNA of collagen type I, going from weak a moderate, was observed at the walls of bronchioles to 12 at 40 week of gestation on human fetal lung.

A different expression pattern for collagens I and III has been reported in chicken ${ }^{30}$ and mice embryos lung. ${ }^{31}$ In the early stages they were present in all areas of the lung primordium, concentrated in the proximal region as branching progressed. Concerning the expression pattern of collagen I, our results were similar to previously published data. ${ }^{30,31}$ It has been mentioned that inhibition of collagen synthesis inhibits lung branching. ${ }^{32}$ However, lung branching was totally normal in collagen I-deficient mice, ${ }^{33}$ showing that collagen I is not essential in the branching of budding regions, because other types of collagens, such as types III and V, replace the collagen type I function.

In other models where branching morphogenesis occurs, as is the case of the submandibular glands of the mouse, a central role of collagen III in the epithelial-mesenchymal interactions and in cleft initiation in glands has been reported by Nakanishi et al ${ }^{34}$ We suggest that this model of branching morphogenesis, where collagens play an important role in the process of division of submandibular glands, might be similar to human lung branching.

Using rat lungs, Amenta et al..$^{35}$ studied the distribution of collagen III, IV and VI, which was expressed in the interstitium between the major airways and blood vessels. They found a close association between collagen I, III, VI and the epithelial basal membrane, suggesting that collagen VI may bind components of the pulmonary ECM and integrate them into a functional unit. These findings suggest an association of collagen I and III with collagen VI which is also located at the epithelium-mesenchyma interface in the human lung. It has
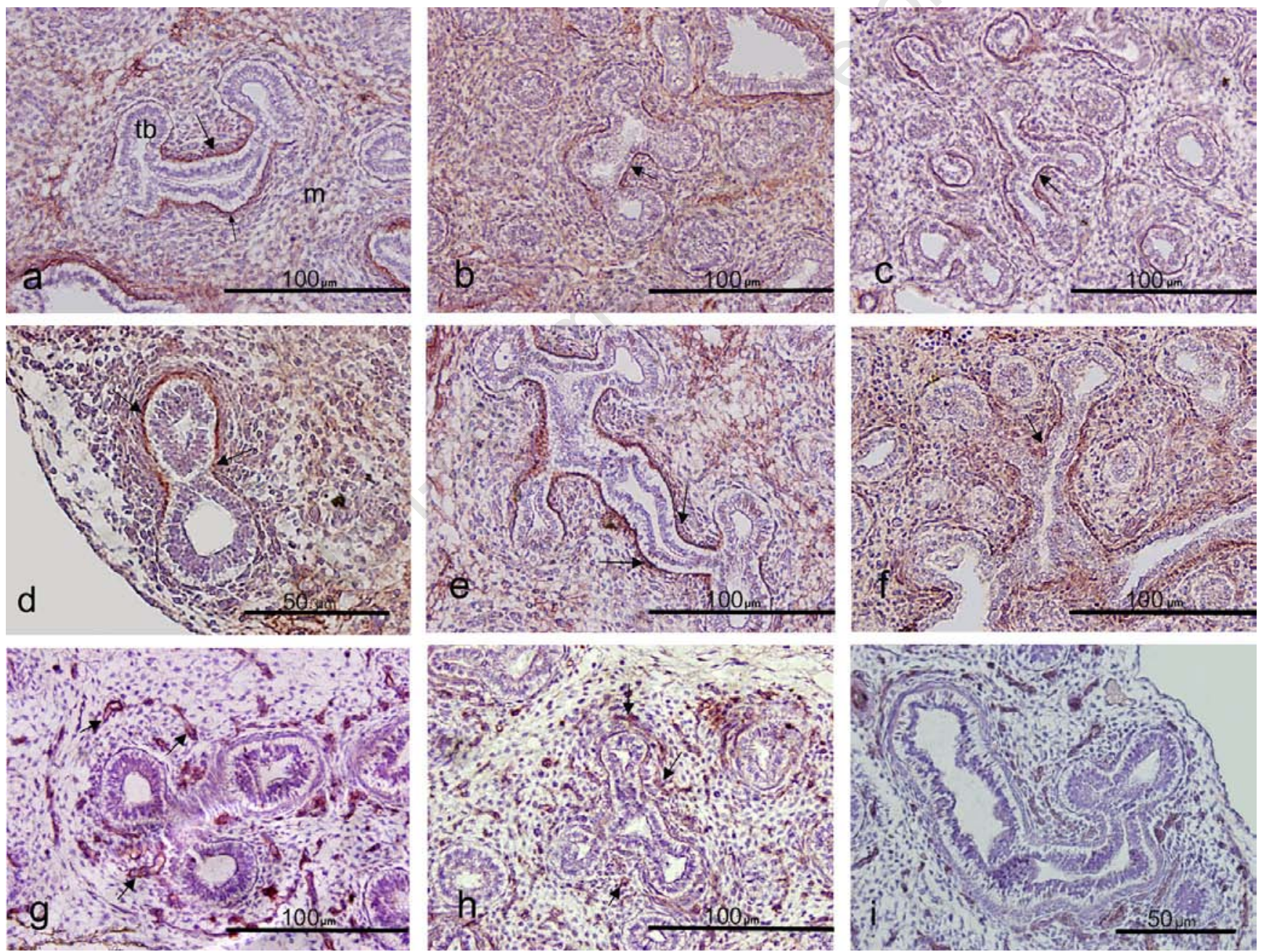

Figure 2. Immunoperoxidase stain for lumican (a-c), decorin (d-f) and biglycan (g-i). From wk 8 post-fertilization time (a, d) proteoglycans were found in the epithelial-mesenchymal interface at the branching site, and it forms a sleeve around bronchiolar ducts (arrows). The surface of the terminal buds is not stained. Between $10 \mathrm{wk}$ pf time (b,e) to 14 wk of gestational age (c, $f)$ the immunoreaction was present in the branching duct cleft. Lumican (c) showed a low inmunoreaction at 14 wk of gestational age. Biglycan (g-i) was found in the blood vessels (arrows) surrounding the terminal bud at 8 (g), 10 (h) and 14 (i) wk. M, mesenchyma; tb, terminal bud. 
been suggested ${ }^{35,36}$ that the contribution of collagen I, III and VI to blood vessel development indicates an important role of these molecules in the mechanical stability of the circulatory system. Therefore, and in agreement with our results, the presence of collagens in the subendothelial region of the blood vessels may indicate their involvement in the early development of blood vessels.

The distribution of the proteoglycans decorin, lumican and biglycan is described here for the first time during the pseudoglandular phase of human lung development. These macromolecules are involved in several functions such as the regulation of protease and antiprotease activity, cell response to growth factors, cell-cell interaction and their interactions with the epithelial ECM molecules, and also in the regulation of ECM assembly. ${ }^{37}$ Experiments with mouse embryonic lung cell cultures using beta-xyloside, a proteoglycan biosynthesis disrupter, reveal that in the absence of chondroitin sulfate the ECM is disturbed and branching morphogenesis is compromised. ${ }^{38}$ Hall et al ${ }^{39}$ studied the expression of versican in human lungs between 28 and 98 days of development and found that this proteoglycan was present in the mesenchyme, but not in the endodermal epithelium and capillaries.

Decorin belongs to the SLRP family and consists of a core protein linked to the glycosaminoglycan chains of chondroitin sulfate or dermatan sulfate, and it is closely related structurally to the proteoglycan biglycan. ${ }^{40}$ Decorin as a component of connective tissue fibers is associated with collagen I and VI, and plays an important role in the assembly of the extracellular matrix..$^{41,42}$ Our results confirm this association between decorin and collagen, where a similar distribution pattern of decorin, biglycan, collagen I and VI was observed in the branching duct clefts, suggesting that they may have a similar role during lung development.

Biglycan consists of a core protein and two chains of chondroitin or dermatan sulfate. The role of this proteoglycan on blood vessel formation is a matter that has not been studied deeply. Biglycan is expressed by human endothelial cells ${ }^{43}$ and in this location it has been reported that it plays a role in the regulation of some type-specific cell functions of endothelial and smooth muscle cells. ${ }^{44}$ In our study we found that the expression of biglycan in the endothelial cells and vascular smooth muscle are of interest and may suggest a similar function related with the early development of blood vessels of the lung during the period analysed.

Lumican is another member of the SLRP family that binds to collagen I through highly charged hydrophilic glycosaminoglycans regu- lating interfibrillar spacing. ${ }^{14,42}$ In fact, Vogel and Trotter ${ }^{15}$ showed that decorin and lumican link to fibrillar collagen in vitro, stabilizing thin fibrils. We also found in this study a similar distribution pattern of lumican, decorin and collagen I in the branching duct clefts of the airway that suggests a similar fibril stabilizing role of collagen at the interface.

In agreement with previous observations conducted by others, ${ }^{25,45}$ we concluded that the distribution pattern of collagens and proteoglycans at the epithelial-mesenchymal interface and in the cleft sites in the developing human lung might indicated that these molecules may play a role in the regulation of the initiation and stabilization of airway bud formation during the branching process. This process may be very important in the airway conducting system of the human fetal lung during the establishment of the pattern for the process of dichotomous division of the bronchial tree.

\section{References}

1. Hilfer SR. Morphogenesis of the lung: control of embryonic and fetal branching. Annu Rev Physiol 1996;58:93-113.

2. Warburton D, Schwarz M, Tefft D, FloresDelgado G, Anderson KD, Cardoso WV. The molecular basis of lung morphogenesis. Mech Dev 2000;92:55-81.

3. Jeffrey PK. The development of large and small airways. Am J Respir Crit Care Med 1998;157:S174-80.

4. Joshi S, Kotecha S. Lung growth and development. Early Hum Dev 2007;83:789-94.

5. Shannon JM, Hyatt BA. Epithelial-mesenchymal interactions in the developing lung. Annu Rev Physiol 2004;66:625-45.

6. Burri PH. Fetal and postnatal development of the lung. Annu Rev Physiol 1984;46:61728.

7. Lwebuga-Mukasa JS. Matrix-driven pneumocyte differentiation. Am Rev Respir Dis 1991;144:452-7.

8. Hocking AM, Shinomura T, McQuillan DJ. Leucine-rich repeat glycoproteins of the extracellular matrix. Matrix Biol 1998; 17:1-19.

9. McEwan PA, Scott PG, Bishop PN, Bella J. Structural correlations in the family of small leucine-rich repeat proteins and proteoglycans. J Struct Biol 2006;155:294-305.

10. San Martin S, Soto-Suazo M, De Oliveira SF, Aplin JD, Abrahamsohn P, Zorn TMT. Small leucine-rich proteoglycans (SLRPs) in uterine tissues during pregnancy in mice. Reproduction 2003;125:585-95.

11. San Martin S, Zorn TMT. The small proteoglycan biglycan is associated with thick collagen fibrils in the mouse decidua. Cell
Mol Biol (Noisy-le-grand) 2003;49:673-8.

12. Iozzo RV. The family of the small leucinerich proteoglycans: key regulators of matrix assembly and cellular growth. Crit Rev Biochem Mol Biol 1997;32:141-74.

13. Hedbom E, Heinegard D. Interaction of a $59-\mathrm{kDa}$ connective tissue matrix protein with collagen I and collagen II. J Biol Chem 1989;264:6898-905.

14. Svensson L, Narlid I, Oldberg A. Fibromodulin and lumican bind to the same region on collagen type I fibrils. FEBS Lett 2000; 470:178-82.

15. Vogel KG, Trotter JA. The effect of proteoglycans on the morphology of collagen fibrils formed in vitro. Coll Relat Res 1987; 7:105-14.

16. Danielson KG, Baribault H, Holmes DF, Graham H, Kadler KE, Iozzo RV. Targeted disruption of decorin leads to abnormal collagen fibril morphology and skinfragility. J Cell Biol 1997;136:729-43

17. Xu T, Bianco P, Fisher LW, Longenecker G Smith E, Goldstein S, et al. Targeted disruption of the biglycan gene leads to an osteoporosis-like phenotype in mice. Nat Genet 1998;20:78-82.

18. Ameye L, Aria D, Jepsen K, Oldberg A, Xu T, Young MF. Abnormal collagen fibrils in tendons of biglycan/fibromodulin-deficient mice lead togaitimpairment, ectopic ossification, and osteoarthritis. FASEB J 2002; 16:673-80.

19. Hausser H, Groning A, Hasilik A, Schonherr E, Kresse. Selective inactivity of TGF-beta/decorin complexes. FEBS Lett 1994;353:243-5.

20. Kolb M, Margetts PJ, Sime PJ, Gauldie J. Proteoglycans decorin and biglycan differentially modulate TGF-beta-mediated fibrotic responses in the lung. Am J Physiol Lung Cell Mol Physiol 2001;280: L1327-34.

21. Yamaguchi Y, Mann DM, Ruoslahti E. Negative regulation of transforming growth factor-beta by the proteoglycan decorin. Nature 1990;346:281-4.

22. Santra M, Mann DM, Mercer EW, Skorski T, Calabretta B, Iozzo RV. Ectopic expression of decorin protein core causes a generalized growth suppression in neoplastic cells of various histogenetic origin and requires endogenous $\mathrm{p} 21$, aninhibitor of cyclin-dependentkinases. J Clin Invest 1997;100:149-57.

23. Moscatello DK, Santra M, Mann DM, McQuillan DJ, Wong AJ, Iozzo RV. Decorin suppresses tumor cell growth by activating the epidermal growth factor receptor. J Clin Invest 1998;101:406-12.

24. Nikitovic D, Katonis P, Tsatsakis A, Karamanos NK, Tzanakakis GN. Lumican, a small leucine-richproteoglycan. IUBMB 
Life 2008;60:818-23.

25. Wright C, Strauss S, Toole K, Burt AD, Robson SC. Composition of the pulmonary interstitium during normal development of the human fetus. Pediatr Dev Pathol 1999;2:424-31.

26. Giachini FR, Carriel V, Capelo LP, Tostes RC, Carvalho MH, Fortes ZB, et al. Maternal diabetes affects specific extracellular matrix components during placentation. J Anat 2008;212:31-41.

27. Soto-Suazo M, San Martin S, Ferro ES, Zorn TM. Differential expression of glycosaminoglycans and proteoglycans in the migratory pathway of the primordial germ cells of the mouse. Histochem Cell Biol 2002;118:69-78.

28. Salgado RM, Favaro RR, Martin SS, Zorn TM. The estrous cycle modulates small leucine-rich proteoglycans expression in mouse uterine tissue. Anat Rec (Hoboken) 2009;292:138-53.

29. Kaarteenaho-Wiik R, Pääkkö P, Herva R, Risteli J, Soini Y. Type I and III collagen protein precursors and mRNA in the developing human lung. J Pathol 2004;203:56774.

30. Abbott LA, Lester SM, Erickson CA. Changes in mesenchymal cell-shape, matrix collagen and tenascin accompany bud formation in the early chick lung. Anat Embryol (Berl) 1991;183:299-311.

31. Heine UI, Munoz EF, Flanders KC, Roberts $\mathrm{AB}$, Sporn MB. Colocalization of TGF-beta 1 and collagen I and III, fibronectin and glycosaminoglycans during lung branching morphogenesis. Development 1990;
109:29-36.

32. Alescio T. Effect of a prolineanalogue, azetidine-2-carboxylic acid, on the morphogenesis in vitro of mouse embryonic lung. J Embryol Exp Morphol 1973;29:439-51.

33. Kratochwil K, Dziadek M, Lohler J, Harbers K, Jaenisch R. Normal epithelial branching morphogenesis in the absence of collagen I. Dev Biol 1986;117:596-606.

34. Nakanishi Y, Nogawa H, Hashimoto Y, Kishi J, Hayakawa T. Accumulation of collagen III at the cleft points of developing mouse submandibular epithelium. Development 1988;104:51-9.

35. Amenta PS, Gil J, Martinez-Hernandez A. Connective tissue of rat lung. II: Ultrastructura llocalization of collagen types III, IV, and VI. J Histochem Cytochem 1988;36:1167-73.

36. Lohler J, Timpl R, Jaenisch R. Embryonic lethal mutation in mouse collagen I gene causes rupture of blood vessels and isassociated with erythropoietic and mesenchymal cell death. Cell 1984;38:597-607.

37. Kreis T, Vale, R. Guidebook to the extracellular matrix and adhesion proteins. 1993, Oxford University Press, Oxford, UK.

38. Spooner BS, Bassett KE, Spooner BS Jr. Embryonic lung morphogenesis in organ culture: experimental evidence for a proteoglycan function in the extracellular matrix. Trans Kans Acad Sci 1993;96:4655.

39. Hall SM, Hislop AA, Pierce CM, Haworth SG. Prenatal origins of human intrapulmonary arteries: formation and smooth muscle maturation. Am J Respir Cell Mol
Biol 2000;23:194-203.

40. Cheng F, Heinegard D, Malmstrom A, Schmidtchen A, Yoshida K, Fransson LA. Patterns of uronosyl epimerization and 4/6-0-sulphation in chondroitin/dermatan sulphate from decorin and biglycan of various bovine tissues. Glycobiology 1994;4: 685-96.

41. Bidanset DJ, Guidry C, Rosenberg LC, Choi HU, Timpl R, Hook. M Binding of the proteoglycan decorin to collagen type VI. J Biol Chem 1992;267:5250-6.

42. Scott PG, Dodd CM, Bergmann EM, Sheehan JK, Bishop PN. Crystal structure of the biglycan dimer and evidence that dimerization is essential for folding and stability of class I small leucine-rich repeat proteoglycans. J Biol Chem 2006;281: 13324-32.

43. Bianco P, Fisher LW, Young MF, Termine JD, Robey PG. Expression and localization of the two small proteoglycans biglycan and decorin in developing human skeletal and non-skeletaltissues. J Histochem Cytochem 1990;38:1549-63.

44. Jarvelainen HT, Kinsella MG, Wight TN, Sandell LJ. Differential expression of small chondroitin/dermatan sulfate proteoglycans, PG-I/biglycan and PG-II/ decorin, by vascular smooth muscle and endothelialcells in culture. $\mathrm{J}$ Biol Chem 1991;266:23274-81.

45. Carlson BM. Embriología humana y biología del desarrollo. 4nd ed. 2005, Elsevier Masson, Barcelona, Spain. 